\title{
Effects of placement and orientation of body-fixed accelerometers on the assessment of energy expenditure during walking
}

Citation for published version (APA):

Bouten, C. V. C., Sauren, A. A. H. J., Verduin, M., \& Janssen, J. D. (1997). Effects of placement and orientation of body-fixed accelerometers on the assessment of energy expenditure during walking. Medical and Biological Engineering and Computing, 35(1), 50-56. https://doi.org/10.1007/BF02510392

DOI:

10.1007/BF02510392

Document status and date:

Published: 01/01/1997

Document Version:

Publisher's PDF, also known as Version of Record (includes final page, issue and volume numbers)

\section{Please check the document version of this publication:}

- A submitted manuscript is the version of the article upon submission and before peer-review. There can be important differences between the submitted version and the official published version of record. People interested in the research are advised to contact the author for the final version of the publication, or visit the DOI to the publisher's website.

- The final author version and the galley proof are versions of the publication after peer review.

- The final published version features the final layout of the paper including the volume, issue and page numbers.

Link to publication

\footnotetext{
General rights

- You may freely distribute the URL identifying the publication in the public portal. follow below link for the End User Agreement:

www.tue.nl/taverne

Take down policy

If you believe that this document breaches copyright please contact us at:

openaccess@tue.nl

providing details and we will investigate your claim.
}

Copyright and moral rights for the publications made accessible in the public portal are retained by the authors and/or other copyright owners and it is a condition of accessing publications that users recognise and abide by the legal requirements associated with these rights.

- Users may download and print one copy of any publication from the public portal for the purpose of private study or research.

- You may not further distribute the material or use it for any profit-making activity or commercial gain

If the publication is distributed under the terms of Article 25fa of the Dutch Copyright Act, indicated by the "Taverne" license above, please 


\title{
Effects of placement and orientation of body-fixed accelerometers on the assessment of energy expenditure during walking
}

\author{
C. V. C. Bouten \\ A. A. H. J. Sauren \\ M. Verduin \\ J. D. Janssen \\ Eindhoven University of Technology, Faculty of Mechanical Engineering, PO box 513, $5600 \mathrm{MB}$,
} Eindhoven, The Netheriands

Keywords-Accelerometry, Energy expenditure, Gravitational acceleration, Kinematic acceleration, Physical activity, Walking

Med. \& Biol. Eng. \& Comput., 1997, 35, 50-56

\section{List of symbols}

$a=$ scalar

$\boldsymbol{a}=$ vector

$|a|=$ modulus of $a$

$\dot{a}=$ time derivative of $a$

$\ddot{a}=$ second time derivative of $a$

$A=$ matrix

\section{Introduction}

INVESTIGATION of the relationship between daily physical activity and health requires an objective method to assess physical activity under daily living conditions with minimal discomfort to subjects. The application of body-fixed accelerometers offer a promising method for this purpose. These sensors register accelerations of the body, and in this way provide an objective and direct measurement of the frequency and intensity of movements during physical activity. Data from studies on gait analysis and ergonomics (BRoUHA, 1960; REswick et al., 1978) have demonstrated a linear relationship between the integral of the modulus of body acceleration (IMA) and energy expenditure for physical activity ( $\mathrm{EE}_{\mathrm{act}}$ ), which is the widely accepted standard reference for physical activity (LAPORTE et al., 1985). These findings initiated the development of portable accelerometers (calculating IMA) to estimate energy expenditure during physical activity. These accelerometers have been successfully evaluated during standardised walking activities in the laboratory (BouTen et al., 1994; MONOTOYE et al., 1983), as well as during habitual physical activity under daily living conditions (HEYMAN et al, 1991; MEIJER et al., 1992).

In order to restrict data acquisition and to minimise the

Correspondence should be addressed to Dr. C. V. C. Bouten; email carlifn@wfw.wtb.tue.nl.

First received 28 August 1995 and in final form 6 August 1996.

IFMBE: 1997 discomfort to subjects, accelerations are generally measured with a single uniaxial or triaxial accelerometer attached to the human body at waist level. The question then arises whether this is the right location of the accelerometer for the most accurate prediction of $E E_{\text {act }}$. It is often assumed that accelerometers should be attached to the lower back, near the body's centre of mass, because movements of the centre of mass reflect movements of the total body (FARRIS, 1987; SMIDT et al, 1971). However, it is also suggested that accelerometers should be attached to those parts of the body where they would register the most activity, i,e. the legs during walking (LAPORTE et al,, 1979; WEBSTER et al, 1982). Washburn and Laporte studied IMA, calculated from uniaxial body-fixed accelerometers with vertical measurement direction at the non-dominant hip and the middle of the back during walking at normal and fast pace in 17 subjects (WASHBURN and LAPORTE, 1988). No significant differences between IMA values at the hip and the back were found. Balogun et al. reported significantly higher IMA values calculated from accelerometer readings at waist level than from accelerometer readings at chest level during walking at 3.2 and $6.4 \mathrm{~km} \mathrm{~h}^{-1}$ in 20 subjects (BALOGUN et al. 1988). However, no conclusive statement about the prediction of $\mathrm{EE}_{\text {acr }}$ from IMA determined at the various locations was given in either of the studies. Apart from a possible influence of measurement location, it is unknown whether the use of several accelerometers at different locations on the body results in a better prediction of $E_{\text {act }}$ than the use of a single accelerometer. Furthermore, it is unclear whether this prediction is infuenced by the measurement direction(s) of the accelerometers.

The output of a body-fixed accelerometer originates from several sources: acceleration due to body movement; gravitational acceleration; extemal vibration, not produced by the body itself; and acceleration due to motion of the tissue under the accelerometer or jolting of the sensor on the body due to loose attachment, eventually resulting in mechanical resonance (REDMOND and HEGGE, 1985). Of these, only the first two sources are directly related to intentional physical activity. The output due to body movement, usually referred to as the 
'kinematic component,' is influenced by the type of activity performed, the part of the body where accelerations are measured, and the measurement direction (BOUTEN et al, 1977). The 'gravitational component' of accelerometer output depends on the orientation of the measurement direction of the transducer with respect to the gravitational field, and may vary between $-1 \mathrm{~g}$ and $1 \mathrm{~g}$. Considering the magnitude of kinematic accelerations occurring during physical activity (ranging from $-6 g$ to $6 g$ at waist level) (BHATTACHARYA et al, 1980), this gravitational component can seriously affect accelerometer output. In order to correct the accelerometer output for the gravitational component, information about the orientation of the sensor within the field of gravity should be available throughout the measurement period. This requires the synchronous recording of the orientation, for example with goniometers or inclinometers (SMEATHERS, 1989; TANAKA et al., 1994), or with film and video (LAFORTUNE and HENNIG, 1991).

Some researchers have tried to use multiple accelerometers to obtain all six degrees of freedom that comprise rigid body motion, and to calculate the spatial orientation of the rigid segment to which the accelerometers are attached by subsequent time integration (LADN and WU, 1991). This approach, however, requires the identification of an initial orientation in space that can serve as the initial orientation for the integration process. It will be obvious that above-mentioned techniques to correct the orientation of accelerometers within the field of gravity have limited possibilities when accelerometers are used for physical activity assessment in subjects moving freely. Therefore, in this area the gravitational component of accelerometer output is often taken for granted. Some authors argue that attachment to locations where (the variation in) rotation with respect to the field of gravity is relatively small, e.g. the trunk or head, is superior to attachment to the limbs (SERVAIS et al,, 1984; WATERS et al., 1973). However, the precise effects of accelerometer orientation on IMA and the prediction of $\mathrm{EE}_{\mathrm{act}}$ has never been studied.

This study investigates the influence of accelerometer placement and orientation on IMA and the assessment of $\mathrm{EE}_{\mathrm{act}}$ during a common daily activity, i.e. walking. IMA, with and without correction for the gravitational component of accelerometer output, is determined from simulated accelerometer outputs at various locations on the human body, by using kinematic data obtained from video recordings of the walking movement and a rigid segment model of the human body. In addition, IMA was determined from the measured accelerometer output at the lower back to compare realistic and simulated IMA values. As walking is almost completely restricted to the sagittal plane (INMAN et al., 1981), a twodimensional approach was used and accelerometer outputs were simulated/measured in the body-fixed antero-posterior (sagittal) and vertical directions. Both simulated and measured IMA values were compared with $E_{\text {act }}$ determined from indirect calorimetry.

\section{Accelerometer output: theory}

Consider the rigid link in Fig. 1, oscillating in the sagittal plane $\left(e_{x}, e_{y}\right.$ plane) about $P$ with $x e_{x}$ and $y e_{y}$ the positions of $P$ with respect to $O, \phi$ the angular deflection of the link in time, and $g$ the gravitational acceleration vector. The acceleration $\ddot{q}$ of an arbitrary point $Q$ at distance 1 from $P$ and at position $q$ with respect the origin $O$ of the inertial system of reference is given by

$$
\ddot{q}=\ddot{q}_{x} e_{x}+\ddot{q}_{y} e_{y}
$$

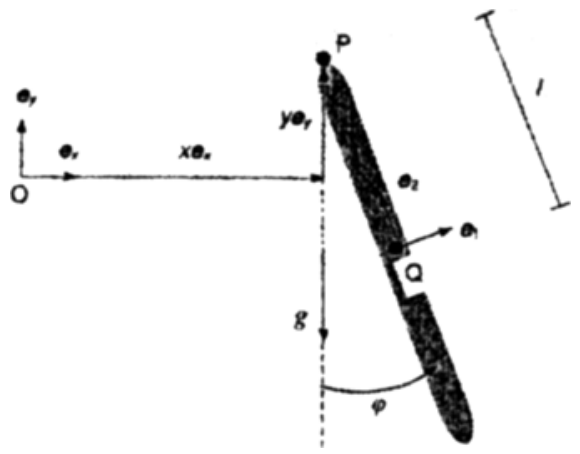

Fig. 1 Rigid link, oscillating in the sagittal plane about $P$, with $x e_{x}$ and $e_{y}$ the positions of $P$ with respect to $O$, $\phi$ the instantaneous deflection of the link with respect to the vector of gravity $(g)$ and $l$ the distance of $Q$ from $P . O . e_{x}$ and $e_{y}$ are fixed in space. $e_{1}$ and $e_{2}$ are body-fixed

with

$$
\begin{aligned}
& \ddot{q}_{x}=\ddot{x}+l \ddot{\phi} \cos (\phi)-l \dot{\phi}^{2} \sin (\phi) \\
& \ddot{q}_{y}=\ddot{y}+l \ddot{\phi} \sin (\phi)+l \dot{\phi}^{2} \cos (\phi)
\end{aligned}
$$

To study the output of body-fixed accelerometers a local bodyfixed system of reference $\left(e_{1}, e_{2}\right)$ is introduced, where

$$
\begin{aligned}
& {\left[\begin{array}{l}
e_{1} \\
e_{2}
\end{array}\right]=R\left[\begin{array}{l}
e_{r} \\
e_{y}
\end{array}\right]} \\
& {\left[\begin{array}{l}
e_{x} \\
e_{y}
\end{array}\right]=R^{\top}\left[\begin{array}{l}
e_{1} \\
e_{2}
\end{array}\right]}
\end{aligned}
$$

with $\boldsymbol{R}$ the rotational transformation matrix of the rigid link with respect to the $e_{x}, e_{y}$ plane.

The output $a_{\theta}$ of an ideal (i.e. no transverse sensitivity) body-fixed accelerometer at point $Q$ on the rigid link with body-fixed vector $\boldsymbol{m}_{\ell}$, denoting the positive measurement direction (Fig. 2), consists of the component of kinematic acceleration $\ddot{q}$ along $\boldsymbol{m}_{\vartheta}$ and the component of gravitational acceleration $\boldsymbol{g}$ along $\boldsymbol{m}_{\vartheta}$ :

$$
a_{0}=(\ddot{q}+g) m_{\theta}
$$

with the acceleration vector $\ddot{q}$ defined by eqn. $1, g=-g e_{y}$ and

$$
\boldsymbol{m}_{0}=\left[\begin{array}{ll}
\boldsymbol{e}_{2} & \boldsymbol{e}_{2}
\end{array}\right]\left[\begin{array}{c}
\cos (\theta) \\
\sin (\theta)
\end{array}\right]
$$

With the use of eqns. 5 and 7 , eqn. 6 can be rewritten as

$$
a_{\theta}=\cos (\phi+\theta) \ddot{q}_{x}+\sin (\phi+\theta)\left(\ddot{q}_{y}-g\right)
$$

The acceleration of a moving body is usually measured with separate linear accelerometers with positive measurement directions along the axes of the body-fixed system of reference. If the acceleration of the rigid link in Fig. 1 is measured with two accelerometers with positive measurement directions

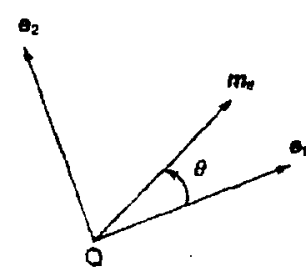

Fig. 2 Defintion of the measurement direction $m_{0}$ of a body-fixed linear accelerometer at point $Q$ with respect to the botyfoxed system of reference $\left(e_{1}, e_{2}\right)$ 
parallel to $e_{1}\left(m_{\theta=0}\right)$ and $e_{2}\left(m_{\theta=\pi / 2}\right)$, their outputs can be described by eqns. 2 and 3 according to

$$
\begin{aligned}
& a_{1}=\ddot{x} \cos (\phi)+\ddot{y} \sin (\phi)+l \ddot{\phi}-g \sin (\phi) \\
& a_{2}=-\ddot{x} \sin (\phi)+\ddot{y} \cos (\phi)+l \dot{\phi}^{2}-g \cos (\phi)
\end{aligned}
$$

During human locomotion $\phi$ is assumed to be relatively small, especially when the accelerometers are fixed to the trunk. Consequentiy, an accelerometer with measurement direction along $e_{2}$ is considerably infiuenced by the opposing gravitational acceleration. Therefore, in practice the output is usually set to zero (adding $1 \mathrm{~g}$ to the output) when the measurement direction is parallel to the $e_{y}$ axis, i.e. when the effect of $g$ is maximai (SERVAIS et al., 1984; SMIDT et al., 1971). This will result in

$$
a_{2}=-\ddot{x} \sin (\phi)+\ddot{y} \cos (\phi)+l \dot{\phi}^{2}-g \cos (\phi)+g
$$

\section{Methods}

\subsection{Protocol}

Two healthy male subjects participated in the study. Their age, body mass and height were 24 years, $63.7 \mathrm{~kg}$, and $1.78 \mathrm{~m}$ for subject 1 , and 23 years, $67.0 \mathrm{~kg}$ and $1.86 \mathrm{~m}$ for subject 2 . The subjects walked at a freely chosen step frequency on a motordriven treadmili* at velocities of $3,4,5,6$ and $7 \mathrm{~km} \mathrm{~h}^{-1}$ for $3 \mathrm{~min}$ at each velocity. Refiective markers with a diameter of $30 \mathrm{~mm}$ were placed at anatomical landmarks on the right side of the subjects' bodies to define a nine-segment model of the human body, consisting of two lower leg + foot segments (LF), two upper leg (UL) segments, two lower arm + hand (AH) segments, two upper arm (UA) segments, and a segment comprising the head and trunk (HT). During the last minute of each walking velocity, body movement in the sagitall plane was recorded on video to calculate body accelerations for the simulation of accelerometer output. Synchronously, accelerations were measured at the lower back. To standardise the effect of footwear on measured accelerometer output, both subjects wore identical sports shoes. During all walking velocities $\mathrm{O}_{2}$ consumption and $\mathrm{CO}_{2}$ production were continuously measured to calculate the metabolic energy expenditure.

\subsection{Measured accelerometer output}

Accelerations were measured at the lower back (lumbar level) with a triaxial accelerometer, consisisting of three uniaxial piezoresistive accelerometerst (range $-10 \mathrm{~g}$ to $10 \mathrm{~g}$, frequency response $0-600 \mathrm{~Hz}, f_{0}=1200 \mathrm{~Hz}$ ) with meam surement directions along the antero-posterior (sagittal), medio-lateral (transversal), and vertical axes of the trunk. As mentioned before, only recordings in the antero-posterior $\left(e_{1}\right)$ and the vertical direction $\left(e_{2}\right)$ were considered. The triaxial accelerometer was attached to the skin of the lower back by an elastic strap around the waist (BouTEN et al., 1994). Bridge amplifiers and batteries for the accelerometers were carried in separate units on both hips. A four-channel FM data recorder\$ was used for analogue recordings of accelerometer output. For each walking velocity, acceleration signals from five subsequent stride periods were used for further analysis. One stride period is defined as the time period between initial beel contact with the ground of the right foot until the next initial

\section{"Quinton}

ticSensors, type 3031-010

\&ुRR 115, Tandberg heel contact of the same foot. Heel contact was characterized by a sharp peak in the acceleration signals, and it could also be determined from the video recordings, which were synchronised in time with accelerometer output.

Accelerometer output was digitised $(100 \mathrm{~Hz})$, low-pass filtered with a fourth-order Butterworth filter $(20 \mathrm{~Hz})$, rectified, and integrated over the complete measurement period $(T)$ to obtain IMA values for both measurement directions. With eqns. 9 and 11 this data processing results in

$$
\mathrm{MA}_{1}=\int_{t=u_{0}}^{t_{n}+T}|\ddot{x} \cos (\phi)+\ddot{y} \sin (\phi)+\ddot{\phi}-g \sin (\phi)| \mathrm{d} t
$$

$$
\begin{aligned}
\mathrm{MA}_{2}= & \int_{t=t_{0}}^{r_{0}+\tau} \mid-\ddot{x} \sin (\phi)+\ddot{y} \cos (\phi) \\
& +l \phi^{2}-g \cos (\phi)+g \mid \mathrm{d} t
\end{aligned}
$$

When accelerations are measured in more than one direction, the best way of data processing to predict $E_{\text {act }}$ is achieved by summation of IMA values from all measurement directions BOUTEN et al. 1994). This data processing is superior to the integration of the total acceleration vector, for example. In the current two-dimensional the data processing referred to is given by

$$
\mathrm{IMA}_{t o t}=\mathrm{IMA}_{1}+\mathrm{IMA}_{2}
$$

In general IMA is calculated over periods of $1 \mathrm{~min}$. For practical reasons and to ensure an equal number of complete movement cycles for each walking velocity in both subjects, this approach was not adopted here. IMA was averaged per second to enable comparisons between subjects and different walking velocities. The average IMA can thus be expressed in units of acceleration $\left(\mathrm{m} \cdot \mathrm{s}^{-2}\right)$. In the following meas (IMA $\mathrm{I}_{1, \text { meas }}$, $\mathrm{IMA}_{2, \text { meas, }}$ IMA $\mathrm{IMt \text {meas }}_{\text {) }}$ is used to indicate IMA, calculated from the measured accelerometer output.

\subsection{Simulated accelerometer output}

The accelerometer output was simulated at the centre of mass of each segment. For comparison with measured acceleration signals, accelerometer output was also simulated at the location of the triaxial accelerometer on the lower back (LB). Although in vivo the attachment of accelerometers to the centre of mass of body segments is impossible, computed accelerations at these locations may be used to approximate accelerations at arbitrary points on the segments, assuming the segments are rigid. To determine the trajectories of the body segments, markers were placed on the right side of the body: at the lateral side of the shoe at the beight of the fifth matatarsal head and the tuber calcanei, the ankle (lateral malleolus), the knee (at the height of the tibila plateau), the hip (greater trochanter), the shoulder (greater tubercle of the humenus), the elbow (lateral epicondyle of the humerus), the wrist (ulnar styloid), the hand (third metacarpophalangeal joint) and the $\mathrm{C} 7 / \mathrm{T} 1$ joint. Marker co-ordinates were collected on video $(25 \mathrm{~Hz})$ and digitized by determining the centroid of pixel clusters using a PC grame grabber** and an image processing package. it

In the subsequent analysis the marker co-ordinates were calibrated against a set of known co-ordinates in the field of view and converted to real two-dimensional co-ordinates in the $\left(e_{x}, \varepsilon_{y}\right)$ system of reference. The data were then smoothed with Wottring's GCVSPL algorithm (WOLTRING, 1986), using

\footnotetext{
**PCvisionPLus, Imaging Tochnology Inc.

†† TIM, TEA Measuring Systems
} 
a cubic B-spline. The spatial resolution of the video images is $4 \mathrm{~mm}(=1$ pixel) in a field of view of $2 \mathrm{~m}$. Given this resolution and a marker diameter of $30 \mathrm{~mm}$, the co-ordinates of the marker centroids could be assessed with an accuracy of $0.6 \mathrm{~mm}$, as described by Peters (PETERS, 1987).

Assuming the movements of the left side of the body were similar to those of the right side, but shifted in time by a half stride period, trajectories of the left leg and arm segments were obtained from the smoothed position/time data of the right leg and arm segments. The marker on the right hip was used as the point of rotation for both right and left UL segments. Locations of the segment centres of mass were obtained using the standards of Dempster (DEMPSTER, 1955). The position/time data of the centres of mass were twice differentiated numerically to obtain the linear accelerations $\ddot{x}$ and $\ddot{y}$ in time. The angles $\phi$ of the individual body segments with the $e_{y}$ axis were calculated from the smoothed marker positions in time, and differentiated to obtain angular velocities $\dot{\phi}$ and accelerations $\ddot{\phi}$.

Angular deflections of the lower leg and lower arm were used as values for $\phi$ of the LF and AH segments, respectively. Simulated accelerometer outputs at the segment centres of mass were then rectified and integrated numerically to obtain the variables $I \mathrm{MA}_{1}$ and $\mathrm{IMA}_{2}$ according to eqns. 12 and 13, and then summed to obtain IMA $\mathrm{A}_{\text {tot }}$ according to eqn. 14, with $T$ representing the time interval of the five stride periods, which were also measured with the accelerometer. To eliminate the influence of accelerometer orientation, simulated IMA variables without the gravitational component were computed using the following equations, marked with the subscript 'cor,' denoting correction for the gravitational component:

$$
\begin{aligned}
& \mathrm{IMA}_{1 . c o r}=\int_{t=t_{0}}^{t_{0}+T}|\ddot{x} \cos (\phi)=\ddot{y} \sin (\phi)+| \ddot{\phi} \mid \mathrm{d} t \\
& \mathrm{IMA}_{2, \text { cor }}=\int_{t=t_{0}}^{t_{0}+T}|-\ddot{x} \sin (\phi)+\ddot{y} \cos (\phi)+| \dot{\phi}^{2} \mid \mathrm{d} t \\
& \mathrm{IMA}_{\text {tot,cor }}=I M A_{1, \text { cor }}+\mathrm{IMA}_{2 . \text { cor }}
\end{aligned}
$$

Simulated IMA variables were averaged per second and expressed in units of acceleration $\left(\mathrm{m} \cdot \mathrm{s}^{-2}\right)$. Comparisons of average simulated IMA values of the five separate strides of each measurement period resulted in a mean difference of less than $3 \%$ for each walking velocity in both subjects. Fig. 3 shows the location of the triaxial accelerometer and the segment centres of mass where accelerometer output is simulated. The local measurement directions at the separate locations are also indicated.

\subsection{Energy expenditure}

For each walking velocity total energy expenditure $\left(\mathrm{EE}_{\text {tot }}\right)$ was determined according to Weir (WEIR, 1949) from $\mathrm{O}_{2}$ consumption and $\mathrm{CO}_{2}$ production, measured with an automated respiratory gas analysers. $\mathrm{EE}_{\text {tot }}$ was determined for the last minute of each walking velocity, when $\mathrm{O}_{2}$ consumption had reached a steady state. $\mathrm{EE}_{\text {act }}$ was calculated as $\mathrm{EE}_{\text {tot }}$ minus the energy expenditure at rest. The last parameter was measured by indirect calorimetry during an overnight stay in a respiration chamber and was referred to as the sleeping metabolic rate. $\mathrm{EE}_{a c t}$ is expressed in $\mathrm{W}$.

ssoxyconbeta, Mijnhardt

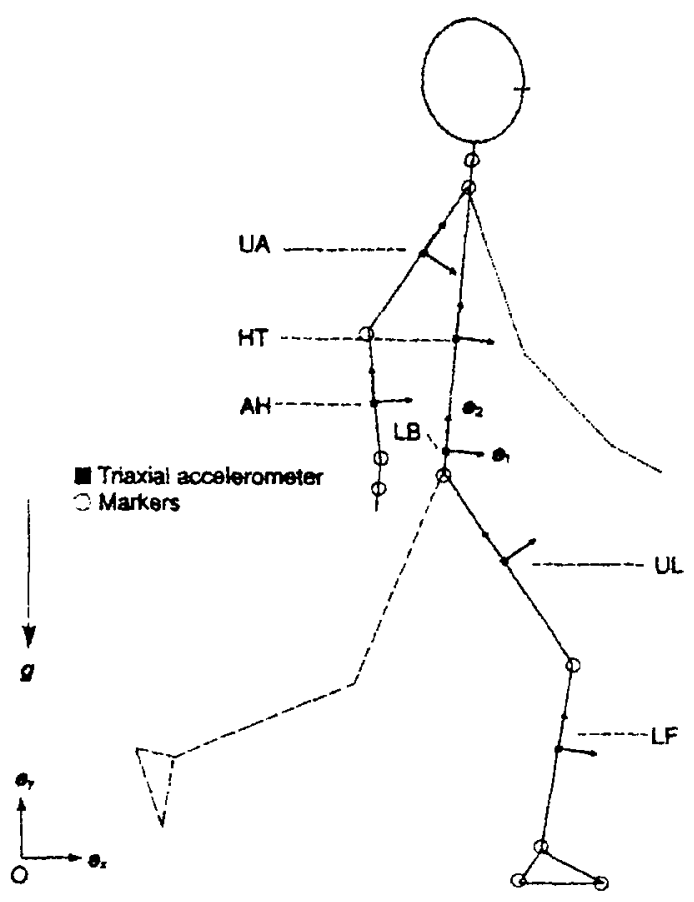

Fig. 3 Locations of the triaxial accelerometer at the lower back and the segment centres of mass where acceleromater output is simulated in the body-fixed $e_{1}$ and $e_{2}$ directions during walking; positions of the markers for definition of the linked segment model of the body are indicated: at the lower back accelerations are also measured using a triaxial accelerometer. $L B=$ low back, $L F=l e g+$ foot segment, $U L=$ upper leg segment, $H T=$ head + trunk segment, $A H=$ lower arm + hand segment, $U A=$ upper arm segment

\subsection{Data analysis}

Measured and simulated (uncorrected) IMA values at the lower back were compared with a paired student t-test, whereas associations between IMA variables and $\mathrm{EE}_{\text {act }}$ were determined with linear regression analysis according to the least-squares principle. Correlation coefficients (Pearson's $r$ ) were calculated from these analyses. Multiple regression analysis, using simulated IMA variables from separate measurement locations, was performed to test whether $\mathrm{EE}_{\text {act }}$ was better predicted from multiple accelerometers than from a single accelerometer. In all statistical analysis a level of $5 \%$ $(p<0.05)$ was taken as the level of significance. As kinematics (and henceforth simulated IMA variables) of the left leg and arm segment were obtained from the phase-shifted kinematics of the right leg and arm segments, results on simulated IMA variables from the left limbs are not presented here.

\section{Results}

Table 1 shows data on energy expenditure, measured IMA variables, and simulated uncorrected IMA values at the lower back for both subjects. Values for the sleeping metabolic rate are $91.4 \mathrm{~W}$ for subject 1 and $88.4 \mathrm{~W}$ for subject 2 . The correlation coefficients between measured IMA variables and $\mathrm{EE}_{a c t}$ are 0.97 for the $e_{1}$ direction, 0.92 for the $e_{2}$ direction, and 0.96 using the summed IMA values from both measurement directions. No significant differences between measured and simulated IMA values at the lower back were found $(p<0.05)$. The correlations for simulated IMA variables at the lower back with $\mathrm{EE}_{a c t}$ were 0.87 for the $e_{1}$ direction, 0.92 for the $e_{2}$ direction, and 0.92 for IMA $_{\text {tot }}$. 
Table 1 Total energy expenditure ( $E E_{\text {trod }}$, energy expenditgure for physical activity (EE $E_{\text {und }}$ and measired and simulated IMA walues (uncorrected for gravitational uccelerstion) at the lower back for each walking velocity in hoth subjects; accelerometer autput values are given as an average for a period of five step cycles

\begin{tabular}{|c|c|c|c|c|c|c|c|c|c|}
\hline \multirow[b]{2}{*}{ subject } & \multirow[b]{2}{*}{$\begin{array}{l}\text { velocity, } \\
\mathrm{km} \cdot \mathrm{h}^{-1}\end{array}$} & \multirow[b]{2}{*}{$\begin{array}{c}E E_{\text {tor }} \\
W\end{array}$} & \multirow[b]{2}{*}{$\underset{W}{\mathrm{EE}_{\text {act }}}$} & \multicolumn{3}{|c|}{ measured IMA } & \multicolumn{3}{|c|}{ simulated IMA at bower back } \\
\hline & & & & $\begin{array}{l}\mathrm{IMA}_{1, \text { meas }}, \\
\mathrm{m} \cdot \mathrm{s}^{-2}\end{array}$ & $\begin{array}{l}\mathrm{MA}_{2 \text { meseass }} \\
\mathrm{m} \cdot \mathrm{s}^{-2}\end{array}$ & 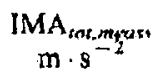 & $\mathrm{IMA}_{\mathrm{m}}$ & $\underset{m \cdot \mathrm{s}_{2,2}}{\mathrm{IM}_{\mathrm{m}}}$ & $\begin{array}{l}\mathrm{IMA}_{\text {ing }} \\
\mathrm{m} \cdot \mathrm{s}^{-2}\end{array}$ \\
\hline \multirow[t]{5}{*}{1} & 3 & 258.9 & 167.5 & 1.0 & 0.7 & 1.7 & $1 \cdot 1$ & 0.8 & 1.9 \\
\hline & 4 & 294.7 & $203 \cdot 3$ & 1.3 & 1.1 & $2 \cdot 4$ & 1.4 & 1.2 & 2.6 \\
\hline & 5 & 317.2 & 225.8 & 1.7 & 1.7 & 3.4 & 1.5 & 1.9 & 3.4 \\
\hline & 6 & 420.0 & 328.6 & 2.3 & 2.6 & 4.9 & $2 \cdot 1$ & 2.6 & 4.9 \\
\hline & 7 & 688.0 & 596.7 & $3 \cdot 2$ & 3.5 & 6.7 & $3 \cdot 3$ & 3.5 & 6.8 \\
\hline \multirow[t]{5}{*}{2} & 3 & 229.8 & 141.4 & 0.8 & 0.9 & 1.7 & 0.7 & 1.2 & 1.9 \\
\hline & 4 & 268.9 & 180.5 & 1.1 & 1.3 & 2.4 & 1.2 & 1.3 & 2.5 \\
\hline & 5 & 336.9 & 248.5 & 1.5 & 20 & 3.5 & 1.7 & 2.0 & 3.7 \\
\hline & 6 & $420 \cdot 0$ & 331.6 & 2.0 & 2.9 & 4.9 & 1.9 & 2.7 & $4 \cdot 6$ \\
\hline & 7 & 552.5 & 464.1 & 2.7 & 3.9 & 6.6 & 2.6 & 4.0 & 6.6 \\
\hline
\end{tabular}

From these results it was concluded that simulated IMA variables may be used to study the influence of accelerometer placement and orientation.

Table 2 shows the simulated IMA ${ }_{\text {tot }}$ values, with and without correction for the gravitational component of accelerometer output, for all modelled segments of the body and the low back. In addition, the percentage difference between corrected and uncorrected $\mathrm{IMA}_{\text {tot }}$ values are included. Overall, simulated IMA values including the gravitational component are higher than IMA values corrected for this component. The largest influences of the gravitational component on IMA were found during walking at $3 \mathrm{~km} \cdot \mathrm{h}^{-1}$. Except for the UA segment, these influences decrease with increasing walking velocity. Similar findings were observed for IMA values in the $e_{1}$ and $e_{2}$ direction. With respect to the place of attachment, the largest influences on the gravitational component were found for the limbs, especially the AH segment, whereas relatively small influences were found for the HT segment and the lower back. These findings were also true for the separate measurement directions, although for each place of attacbment deviations in the $e_{1}$ direction were larger than in the $e_{2}$ direction.

With respect to the relationships between simulated IMA variables and $E E_{a c i}$, strong significant correlations were found for each place of attachment and for values with and without correction for the gravitational component of accelerometer output $(r=0.75-0.94 p<0.05)$. The highest correlation with $\mathrm{EE}_{a c t}$ was observed for IMA along the $e_{2}$ direction at the LF segment. At this segment and at the lower back, correction for the gravitational component resulted in equal or higher correlations with $\mathrm{EE}_{\text {act }}$. At the other places of attachment, correction for the gravitatational component resulted in equal or lower correlations. Regarding the separate measurement directions, the correlations between simulated IMA variables (with or without gravitational component) and $\mathrm{EE}_{\text {act }}$ higher for the $e_{2}$, than for the $e_{1}$ directions. The opposite was true for measured IMA: here, the correlation with $\mathrm{EE}_{\text {act }}$ for measured IMA in the $e_{1}$ direction was higher than for the $e_{2}$ direction. In practice, however, IMA values from orthogonal measurement directions are summed $\left(\mathrm{IMA}_{\text {fot }}\right.$ ) to predict $\mathrm{EE}_{\text {acr }}$.

The explained percentage of the variance of $E_{a c t}$ from measured and simulated $I M A_{t o l}$, with and without gravitational component, at the various places of attachment $\left(r^{2}\right)$ is shown in Fig. 4. 94\% of the variance can be predicted from the measured IMA $\mathrm{A}_{\text {ot. }}$. The predictability of the variance of $\mathrm{EE}_{\text {act }}$ from simulated $I M A_{t o r}$ at this location is only $4 \%$ higher when corrected for the gravitational component than when including this component $\left(89 \%\right.$ for $\mathrm{IMA}_{\text {sot.cor }}$ and $85 \%$ for $\left.\mathrm{IMA}_{\text {to }}\right)$. Maximal differences in the predicted variance in $E E_{a c t}$ from accelerometer output with and without gravitational component were found for the upper leg, where the difference in predictability from $\mathrm{IMA}_{\text {tos }}$ with and without the gravitational component is $5 \%$, and the difference in predictability from $\mathrm{IMA}_{1}$ with and without gravitational component is $10 \%$. In both cases the prediction of $\mathrm{EE}_{\alpha c t}$ became worse after correction for the gravitational component. By using a multiple regression analysis, including the simulated $I M A_{t o t}$ variables

Tabie 2 Simulated IMA between simulated $I M A_{\text {sax }}$ values with and without the gravitational component $\left(I M A_{\text {tot }}-I M A_{\text {lox.cor }}\right.$ ) expressed as a percentage of the value without gravitational component; data are given for simulated places of attachment at the modelled segment centres of mass and the lower back

\begin{tabular}{|c|c|c|c|c|c|c|c|c|c|c|c|c|c|c|c|c|c|c|c|}
\hline \multirow[t]{2}{*}{ subject } & \multirow{2}{*}{$\begin{array}{l}\text { velocity } \\
\mathrm{km} \cdot \mathrm{h}^{-1}\end{array}$} & \multicolumn{6}{|c|}{$\mathrm{MMA}_{\text {tot }} \mathrm{m} \cdot \mathrm{s}^{-2}$} & \multicolumn{6}{|c|}{$\mathrm{MAA}_{\text {rot } .0 \mathrm{or}} \mathrm{m} \cdot \mathrm{s}^{-2}$} & \multicolumn{6}{|c|}{ A, $_{1} \% \mathrm{IMA}_{\text {tor,cior }}$} \\
\hline & & LB & LF & UL & $\mathrm{HT}$ & AH & UA & LB & LF & UL & $\mathrm{HT}$ & $\mathrm{AH}$ & UA & LB & LF & UL. & HT & $\mathrm{AH}$ & UA \\
\hline \multirow[t]{5}{*}{$I$} & 3 & 1.9 & 7.9 & 5.0 & $2 \cdot 1$ & 6.8 & $3 \cdot 2$ & 1. & 4.8 & 2.7 & 1.8 & 3.4 & $2 \cdot 1$ & $25 \cdot 0$ & 65.7 & 86.8 & 16.5 & 98.9 & 58.2 \\
\hline & 4 & 2.6 & 8.8 & 7.2 & $3 \cdot 2$ & 8.7 & 4.0 & $2 \cdot 1$ & 6.0 & 5.3 & 2.9 & 4.5 & 2 & $20-2$ & 47.7 & 36 & 8.4 & 91.8 & 52.8 \\
\hline & 5 & 3.4 & 11.7 & 7.9 & 3.7 & 9.6 & $5 \cdot 1$ & 3.2 & 5.5 & 7.6 & 3.5 & $5 \cdot 3$ & 3. & 6.6 & 54.0 & 44.8 & 6.4 & 82.8 & 34.9 \\
\hline & 6 & 4.9 & 12.7 & 9.0 & 4.7 & 12.1 & 5.7 & 4.8 & 8.6 & 6.5 & 4.7 & 7.0 & 4.4 & $3 \cdot 2$ & 48.3 & 38.8 & 3.5 & 72.2 & 30.8 \\
\hline & 7 & 6.8 & 14.6 & 10.8 & 5.8 & 13.9 & 7.9 & 6.7 & 10.7 & 8.1 & 5.7 & 8.3 & 6.0 & 1.4 & 35.8 & 33.8 & 0.3 & 67.9 & 31.3 \\
\hline \multirow[t]{5}{*}{ 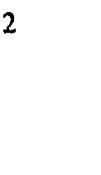 } & 3 & 1.9 & 6.5 & 4.9 & 1.0 & 5.4 & 2.2 & 1.6 & 4.1 & 2.3 & 0.6 & 1.6 & 0.9 & 24.4 & 59.3 & 110.5 & 50.2 & 233.9 & 148.5 \\
\hline & 4 & 2.5 & 8.7 & 6.2 & 2.8 & 6.6 & 3.2 & $2 \cdot 3$ & 5.7 & 4.3 & 2.6 & 3.5 & $2 \cdot 3$ & $11 \cdot 3$ & 53.4 & 46.3 & 5.8 & 89.2 & 39.8 \\
\hline & 5 & 3.7 & 10.5 & 7.2 & 3.0 & 8.8 & 4.3 & 3.5 & 7.2 & 5.1 & 2.9 & 4.7 & 2.9 & 8.2 & 45.5 & 41.7 & 4.1 & 88.9 & 45.3 \\
\hline & 6 & 4.6 & 13.3 & 9.0 & 4.7 & 10.5 & 5.7. & 4.6 & 9.7 & 6.8 & 4.5 & 6.0 & 4.5 & -0.1 & 37.5 & 32.0 & 4.0 & 75.4 & 28.2 \\
\hline & 7 & 6.6 & 16.3 & 11.9 & 5.9 & 13.8 & 8.5 & 6.7 & 12.5 & 9.7 & 5.8 & 8.9 & 6.2 & -0.3 & 29.7 & 22.4 & 2.4 & 55.8 & 38.3 \\
\hline
\end{tabular}

for legends indicating the place of attachment, see Fig. 3 


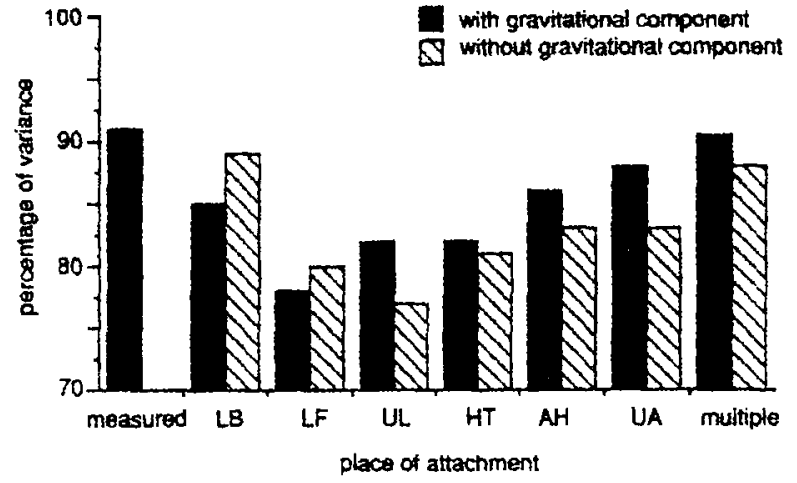

Fig. 4 Explained percentage of the variance of $E E_{\text {act }}$ from measured IMA and from simulated IMA at various locations on the body, with and without correction for the gravitational component of accelerometer output, during walking; the predictability of $E E_{a c r}$ using the simulated IMA values from all locations is also included; for abbreviations see Fig. 3

from all 'measurement' locations, $90 \%$ of the variance of $\mathrm{EE}_{a c t}$ can be predicted. Correction for the gravitational components of these variables did no result in an improvement of the prediction of $\mathrm{EE}_{\text {act }}(88 \%)$.

\section{Discussion}

Although the effects of accelerometer placement and orientation on IMA are considerable (Table 2), their influence on the correlation with $\mathrm{EE}_{\text {act }}$ is negligible. With respect to the place of attachment, IMA at all examined locations on the body may be used to predict $E_{\text {acs }}$ with high accuracy, whereas the improvement in the prediction of $\mathrm{EE}_{\text {act }}$ using the output from multiple accelerometers on several locations on the body seems too slight to compensate for the extra discomfort to subjects. The best prediction of $\mathrm{EE}_{a c t}$ was obtained from the measured IMA variables at the lower back $(r=0.92-0.97)$. These results are comparable to those reported by Balogun et al. and Haymes and Bymes, who reported correlations of 0.92 and 0.94 , respectively, between energy and expenditure and IMA measured in vertical direction with a body-fixed uniaxial accelerometer at waist level during walking (BALOGUN et al., 1989; HAYMES and BYRNES, 1993). The influence of accelerometer orientation on IMA was evident, especially at the limbs and during the lowest walking velocities. This is not surprising, as the (change in) orientation, and therefore the gravitational component of accelerometer output, is greater at the limbs than at the HT segment. Furthermore, the gravitational component remains about the same with increasing walking velocities, whereas the kinematic component of acceleratometer output becomes larger and its influence on IMA decreases at higher walking velocities (Table 2).

The stronger influence of the gravitational component in the $e_{1}$ direction compared to the $e_{2}$ direction might also have been expected, because of the preceding addition of $1 \mathrm{~g}$ to the accelerometer output in the $e_{2}$ direction (eqn. 11). Correction for the gravitational component did, not on average, result in an improvement of the prediction of $\mathrm{EE}_{\alpha c t}$. For example, the variance in $\mathrm{EE}_{a c t}$ predicted from the simulated $\mathrm{IMA}_{\text {tot }}$ at the lower back (the place of attachment that is adopted in most studies on physical activity assessment) was not significantly higher $(4 \%)$ after correction for the gravitational component. Considering the small differences between IMA variables with and without the gravitational component, and the complicated techniques required to correct for this component, it is concluded that correction is not worth the effort.

A possible explanation for the negligible influences of placement and orientation of body-fixed acceleratometers on the prediction of $\mathrm{EE}_{a c t}$ is that measurement of any (increasing) aspect of the movement pattern (at any place on the human body) is representative of the (increasing) energy expenditure required for that movement. This is emphasized by the fact that correlations between $\mathrm{EE}_{u c t}$ and the integral of the modulus of the gravitational component alone range from $r=0.52$ in $e_{2}$ direction at the low back to $r=0.92$ in $e_{2}$ direction at the upper arm. Thus, even if no information about the intensity (acceleration) of the walking movement is available, and there is only some indication about the (change in) orientation of body segments within the filed of gravity, $\mathrm{EE}_{\text {act }}$ can be predicted with reasonable accuracy.

Apart from accelerations due to body movement and gravity, the output of body-fixed accelerometers may result from external vibrations and vibrations due to loose attachment of the sensor and visceral motion of the soft tissue under the sensor. External vibrations can considerably influence the accelerometer output under daily living conditions. Although these vibrations can be attenuated by adequate filtering techniques, contact of the accelerometer (or the subject wearing it) with vibrating external sources such as vehicles or machinery, may pose a major problem when frequencies of the external sources are interfering with frequencies of habitual human movement. For example, the vibration of a power lawn mower $(5-6 \mathrm{~Hz})$ or ground vehicles will affect accelerometer output

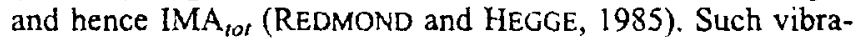
tions, however, could not be expected to interfere with the laboratory measurements in this study.

The accelerometer should be properly fixed to the body in order to avoid the sensor moving or jolting on the skin. Attachment directly to the skin is essential, because the movement of clothes will cause artefacts in the accelerometer output. The accelerometer preferably fixed with adhesive tape or elastic straps. In this way, a firm attachment with minimal discomfort to subjects is achieved. The soft tissue layer under the sensor may still affect Kitazaki and Griffin studied the resonant behaviour of skin-mounted accelerometers attached with double-sided adhesive tape to the skin over the third lumbar vertebra (KITAZAKI and GFIFFIN 1995). During a free vibration test they found resonant frequencies as low as $15 \mathrm{~Hz}$ (range 15-38 Hz) when using an accelerometer with similar measures as the triaxial accelerometer used in this study (contact surface $40 \mathrm{~mm} \times 30 \mathrm{~mm}$; total mass $16 \mathrm{~g}$ ). As $99 \%$ of the acceleration power during walking is concentrated below $15 \mathrm{~Hz}$ (ANTONSSON and MANN, 1985) and the bulk of acceleration power in the upper body ranges from 0.8 to $5 \mathrm{~Hz}$ (CAPPOSSO, 1982), similar resonant frequencies will probably not have affected the present measurements of accelerometer output.

The frequency content of body movement during walking may, however, have influenced the assessment of simulated accelerometer outputs from video recordings. The relatively low sample frequency of these recordings $(25 \mathrm{~Hz})$ probably resulted in aliasing errors during the determination of marker co-ordinates in time. Furthermore, this method of simulating accelerometer output is affected by spatial digitising inaccuracies $(0.6 \mathrm{~mm})$ and the assumption that body segments are rigid. The double differentiation of the position/time data and the subsequent integration of the rectified acceleration signals to obtain IMA may have amplified these inaccuracies. Measured accelerometer outputs, on the other hand, were digitised at $100 \mathrm{~Hz}$ and integrated only once. Despite the difference in data analysis, no significant differences between measured and simulated IMA variables at the lower back word found and 
both variables to accurately assess $\mathrm{EE}_{\text {cct }}$. However, given that only two subjects were studied and the results were obtained from standardised walking movements under laboratory conditions, care should be taken in generalising the results to normal daily living conditions.

Further research during a variety of physical activities and with more subjects is necessary to provide conclusive statements about the effects of placement and orientation of bodyfixed accelerometers on the assessment of energy expenditure during daily physical activity. Nevertheless, this study has aiready shown new aspects of the use of body-fixed accelerometers for physical activity assessment. It had provided information in addition to the studies of Balogun et al. and Washburn and Laporte who studied the place of attachment of accelerometers, but did not include energy expenditure and/or gravitational acceleration in their investigations (BALOGUN et al., 1988; WASHBURN and LAPORTE, 1988). Furthermore, it has refuted the suggestion that accelerometers for the assessment of $\mathrm{EE}_{a c t}$ should always be attached to locations where (the change in) orientation with respect to the field of gravity is minimal (SERvaIS et al., 1984; WATERS et al., 1973).

Acknowledgments-The authors would like to thank P. van Asperdt for assistance during the analysis of the video data.

\section{References}

ANTONSSON, E. K., and MANN, R. W. (1985): 'The frequency content of gait,' J. Biomech., 18, pp. 39-47

Balogli, J. A. Amusa, L. O., and ONewadlime, I. U. (1988): 'Factors affecting Caltrac and Calcount accelcrometer output,' Phys. Ther., 68, pp. 1500-1504

BAlogun, J. A., MARTN, D. A., and Clendentn, M. A. (1989): 'Calorimetric validation of the Caltrac accelerometer during level walking,' Phys. Ther., 69, pp. 501-509

Bhattacharya, A., MCCuTCheON, E. P., SChVARTz, E., and GREENLEAF, J. R. (1980): 'Body acceleration distribution and $\mathrm{O}_{2}$ uptake in humans during running and jumping,' J. Appl. Physiol., 49, pp. $881-887$

BOUTEN, C. V. C., WesterterP, K. P., Verdun, M., and JANSSEN. J. D. (1994): 'Assessment of energy expenditure for physical activity using a triaxial accelerometer,' Med. Sci. Sports Exenc., 26, pp. 1516-1523

BOUTEN, C. V. C., KOEKKOEK, K. T. M., VERDUN, M., KODDE, L., and JANSSEN, J. D. (1977): "A triaxial accelerometer and portable data processing unit for the assessment of daily physical activity, IEEE Trans. on Biomed. Eng. March 1997

BRoUhA, L. (1960): 'Evaluation of requirements of jobs' 'Physiology in industry' (Pergamon Press, Oxford) pp. 94-108

CAPPOZZO, A. (1982): 'Low frequency self-generated vibration during ambulation in normal men,' J. Biomech., 15, pp. 599-609

DEMPSTER, W. T. (1955): 'Space requirements of the seated operator, geometrical kinematic and mechanical aspects of the body with special reference to the limbs.' Technical Report 55-159, Wright Air Development Center, Wright Patterson Air Force Base, Ohio, USA

FARRIS, D. S. (1987): 'Prototype development of a system providing for initial assessment of the dymamics/kinematic of bipedal motion.' Proc. 10th Ann, Conf. RESNA, San Jose, California, pp. $726-728$

HAYMES, E. M., and BYRNES, W. C. (1993): 'Comparison of walking and nunning energy cost using the Caltrac and indirect calorimetry, Med. Sci. Sports Exerc., 25, pp. 1365-1369
HEYMAN, M. B., FUSS, P., YOUNG, V. R., EVANS, W, J., and RBERTS, S. B. (1991): Prediction of total energy expenditure using the Caltrac activity monitor,' Int. J. Ober., 15, (Si), p. 23

INMAN, V. T., RALSON, J. J., and TODD, F. (1981): 'Human walking' (Williams Wilkins. Baltimore) pp. $1-21$

KITAZAKI, S., and GRIFFN, M. J. (1995): 'A data correction method for the surface measurement of vibration on the body,' $J$. Bionrech., 28, pp. 885-890

LADIN, Z., and WU; G. (1991): 'Combining position and acceleration measurements for joint force estimation,' $J$. Biomech. 24, pp. $1173-1187$

LAFORTUNE, M. A., and HENNIG E. M. (1991): 'Contribution of angular motion and gravity to tibial acceleration,' Med. Sci. Sports Med., 23, pp. 360-36j

LAPORTE, R. E., KULLER, L. H., and KUPFER, D. J. (1979): 'An objective measure of physical activity for epidemiological research,' Am. J. Epidemiol., 109, pp. 158-167

LAPORTE, R. E., MONTOYE, H. J., and CASPERSEN, C. J. (1985): 'Assessment of physical activity in epidemilogical research: problems and prospects,' Pub. Health Rep., 100, pp. 131-146

Mener, G. A. L., WesterterP, K. R., VAN Hulsel, A. M. P., and TEN HOOR, F. (1992): 'Physical activity and energy expenditure in lean and obese adult human subjects.' Eur. J. Appl. Physiol., 65, pp. $525-528$

MONTOYE, H. J., WASHBURN, R., SERVAIS, S., ERTL, A., WEBSTER, J. G., and NAGLE, F. J. (1983): 'Estimation of energy expenditure by a portable accelerometer,' :Med. Sci. Sports Exerc., 15, pp. 403-407

PETERS, G. W. M. (1987): 'Tools for the measurement of stress and strain fields in soft tissue.' PhD Thesis, University of Limburg, The Netheriands

REDMOND, D. P., and HegGe, F. W. (1985): 'Observations on the design and specification of a wrist-worn human activity monitoring system,' Behav. Res. Meth. Instr. Comp., 17, pp. 659-669

Reswick, J., Perry, J., ANTONelli, D., Si, Ni, and Freeborn, C. (1978): 'Prcliminary evaluation of the vertical acceleratin gait analyzer' (VAGA). Proc. Gth Ann. Symp. on External Control Extremities, Dubrovnik, Yugoslavia, pp. 305-314

Servals, S. B., Webster, J. G., and MONTOYE, H. J. (1984): 'Estimating human energy expenditure using an accelerometer device,' J. Clin. Eng., 9, pp. 159-170

SMEATHERS, J. E. (1989): 'Measurement of transmissibility for the human spine during walking and running,' Clin. Biomech., 4, pp. 34.40

SMIDT, G. L., ARORA, J., and JOHNSTON, R. C. (1971): 'Accelerographic analysis of several types of walking,' Am. J. Phys. Med, 50, pp. 285-300

TANAKA, S., YAMAKOSHI, K., and ROLFE, P. (1994): 'New portable instrument for long-term ambulatory monitoring of posture change using miniature electro-magnetic inclinometers,' Med. Biol. Eng. Comp., 32, pp. 357-360

WASHBURN, R. A., and LAPORTE, R. e. (1988): 'Assessment of walking behaviour: effects of speed and monitor position on two objective physical activity monitors,' Res. Q Exerc. Sports, 59, pp. 83-85

WATERS, R. L., MORRIS, J., and PERRY, J. (1973): Translational motion of the head and trunk during normal walking,' $J$. Biomech., 6, pp. 167-172

WeBSTER, J. B., MESSIN, S., MULLANEY, D. J., and KRIPKE, D. F. (1982): 'Transducer design and placment for activity recording;' Med. Biol. Eng. Comp., 20, pp. 741-744

WEIR, J. B. DE (1949): 'New methods for calculating metabolic rate with special reference to predict protein metabolism,' J. Physiol, 109, pp. $1-9$

WOLTRNO, H. J. (1986): 'A Fortran package for generalized, crossvalidatory spline smoothing and differentiation,' $A d v$. Eng. Softw., 8, pp. 104-113 